\title{
Microstructure and Properties of Sulfoaluminate Cement-Based Grouting Materials: Effect of Calcium Sulfate Variety
}

\author{
Jianwu Zhang $D^{D},{ }^{1}$ Xuemao Guan, ${ }^{2}$ Xiao Wang, ${ }^{1}$ Xianwei Ma, ${ }^{1}$ Zhixin ${ }^{1},{ }^{1}$ Zhuoyue Xu, \\ and Biao Jin ${ }^{1}$ \\ ${ }^{1}$ School of Materials and Chemical Engineering, Henan University of Urban Construction, Pingdingshan 4670362, China \\ ${ }^{2}$ School of Material Science and Engineering, Henan Polytechnic University, Jiaozuo 454000, China \\ Correspondence should be addressed to Jianwu Zhang; 20181023@hncj.edu.cn
}

Received 6 November 2019; Accepted 31 March 2020; Published 25 April 2020

Academic Editor: Veronica Calado

Copyright ( 2020 Jianwu Zhang et al. This is an open access article distributed under the Creative Commons Attribution License, which permits unrestricted use, distribution, and reproduction in any medium, provided the original work is properly cited.

\begin{abstract}
Effect of calcium sulfate variety on the microstructure and properties of cement-based grouting materials made by sulfoaluminate cement clinker, calcium sulfate resource, and quicklime was investigated in this paper. Isothermal calorimetric, XRD, DTA-TG, and SEM-EDS were used to characterize the reaction process of cement-based grouting materials. The mechanical property and expansion of the harden body were also tested. The results showed that (1) the formation of ettringite can be completed during the first $2 \mathrm{~h}$ when gypsum was selected, causing nonexpansion of the harden body, and ettringite tends to be precipitated near the clinker grain, which has a negative influence on the "skeleton effect" of ettringite, resulting in lower strength of the hardened body. (2) Ettringite can be continually and slowly precipitated when an anhydride was chosen, and the hardened body shows significant expansion characteristic. Besides, ettringite in anhydride paste tends to be precipitated in the form of complex interleaving, which can generate a positive influence on mechanical property of the hardened paste.
\end{abstract}

\section{Introduction}

Sulfoaluminate cement has significant advantages compared with Portland cement, such as lower sintering temperature of the clinker, less limestone consumption, and lower carbon dioxide emissions [1-5]. Therefore, the sulfoaluminate cement can be regarded as a kind of low-carbon environmentfriendly cementitious materials. The sulfoaluminate cement clinker is mainly composed of $\mathrm{C}_{4} \mathrm{~A}_{3} \overline{\mathrm{S}}$ (ye'elimite) and $\mathrm{C}_{2} \mathrm{~S}$ (belite). In addition, it also contains some trace minerals, such as $\mathrm{CA}$ and $\mathrm{C}_{12} \mathrm{~A}_{7}[6-10]$.

Ettringite is one of the most important hydration products of sulfoaluminate cement [11-17]. Sulfoaluminate cement has shown characteristics of rapid hardening, high early strength, and microexpansion which is mainly attributed to large number of ettringite formation in the hydration process [18-20]. Ye'elimite has a decisive role for the formation of ettringite in the system of sulfoaluminate cementitious material. There are two ways for the formation of the ettringite crystal in the hydration process of ye'elimite $[21,22]$. First, ye'elimite in presence of a sulfate source and in aqueous medium will form long columnar ettringite and amorphous gibbsite $\left(\mathrm{AH}_{3}\right)$ according to equation (1) in the early hydration stage, causing rapid hardening and high early strength of the sulfoaluminate cement paste. Second, calcium oxide or calcium hydroxide can also react with aluminum hydroxide and calcium sulfate to form acicular ettringite (equation (2)), causing rapid coagulation and expansion characteristic.

$$
\begin{aligned}
\mathrm{C}_{4} \mathrm{~A}_{3} \overline{\mathrm{S}}+2 \mathrm{C} \overline{\mathrm{S}}+38 \mathrm{H} \longrightarrow \mathrm{C}_{3} \mathrm{~A} \cdot 3 \mathrm{C} \overline{\mathrm{S}} \cdot 32 \mathrm{H} \text { (ettringite) } \\
+2 \mathrm{AH}_{3} \text { (aluminum hydroxide) }
\end{aligned}
$$

$$
\begin{aligned}
3 \mathrm{CH}+\mathrm{AH}_{3}+3 \mathrm{C} \overline{\mathrm{S}}+26 \mathrm{H} & \longrightarrow \mathrm{C}_{3} \mathrm{~A} \cdot 3 \mathrm{C} \overline{\mathrm{S}} \cdot 32 \mathrm{H} \\
\mathrm{C}_{4} \mathrm{~A}_{3} \overline{\mathrm{S}}+18 \mathrm{H} & \longrightarrow \mathrm{C}_{3} \mathrm{~A} \cdot \mathrm{C} \overline{\mathrm{S}} \cdot 12 \mathrm{H} \text { (monosulfate) } \\
& +2 \mathrm{AH}_{3}
\end{aligned}
$$


According to the basic hydration characteristic of ye'elimite, the authors have used the sulfoaluminate cement clinker, natural anhydride, and quicklime to prepare a novel grouting material in previous studies, which had a significant rapid hardening, early strength, and microexpansion characteristics compared with Portland cement-based grouting material [23].

Calcium sulfate source is an important auxiliary mineral material, which can provide the necessary sulfate ions for the formation of ettringite in the ye'elimite hydration process. The ye'elimite will be completely converted to ettringite when the calcium sulfate is sufficient. Once the sulfate source is depleted, monosulfate (AFm) is formed according to equation (3). The amount of added calcium sulfate strongly modifies the ettringite to a monosulfate mass ratio, which will have a significant impact on the macroscopic properties of the material system. The authors' previous work also proved that the amount of calcium sulfate could affect the hydration process of ye'elimite and strongly influence the macroscopic properties of the sulfoaluminate cement clinker-natural anhydride-quicklime ternary system [23]. In fact, the calcium sulfate variety (gypsum, basanite, or anhydride) is another key issue to affect the precipitation of ettringite in addition to the influence of the calcium sulfate content $[24,25]$. This is mainly because different types of calcium sulfate source have significantly different dissolution and release rate of sulfate ions, which is strongly bound to affect the ettringite formation in the ye'elimite hydration process. However, the relevant research about the effect of calcium sulfate variety on the hydration of the $\mathrm{C}_{4} \mathrm{~A}_{3} \overline{\mathrm{S}}-\mathrm{CaSO}_{4}-\mathrm{CaO}$ ternary material system is quite limited. Based on this situation, this paper mainly studies the effect of calcium sulfate variety on the hydration of the sulfoaluminate cement clinker-calcium sulfate-quicklime ternary material system. Due to the rapid condensation rate of basanite, it is unfavorable to the fluidity of grouting slurry [24]. Therefore, gypsum and anhydride are chosen. Through the research work of this paper, the influence mechanism of a calcium sulfate variety on the hydration of the ultrafine sulfoaluminate cement clinker-calcium sulfate-quicklime ternary grouting material system will be revealed, and it also can provide some theoretical direction for the selection of calcium sulfate resource on the sulfoaluminate cement clinker-calcium sulfate-quicklime ternary grouting material system.

\section{Materials and Test Methods}

2.1. Materials. The manufacturer, component, and particle size distribution of ultrafine sulfoaluminate cement (CSA) clinker and quicklime were described in literature [23] as the same. Pure gypsum was purchased from Jiaozuo gypsum Co. Ltd. Anhydrite was prepared by heating the pure gypsum at $700^{\circ} \mathrm{C}$ for $4 \mathrm{~h}$ [24]. Figure 1 shows the X-ray diffraction pattern (XRD) of two kinds of calcium sulfate resources. The pure gypsum and anhydride were then ground until they passed a $25 \mu \mathrm{m}$ sieve. The dissolution rate of two kinds of calcium sulfate resources in saturated lime water at room temperature was tested by an ion exchange neutralization method when the water-to-calcium sulfate ratio is $100: 5$, given in Table 1.
2.2. Mix Proportion of Experiment. The better proportion of between ye'elimite, calcium sulfate, and quicklime can be obtained based on the previous research [23]. Depending on the calcium sulfate variety, the corresponding specimen will be named hereafter CSA-G and CSA-A. The water-to-cement ratio was $1: 1$. Besides, the content of gypsum in CSA$G$ was increased appropriately in order to maintain the consistency of calcium sulfate content in the two groups. The water consumption was also reduced accordingly in CSA-G correspondingly.

\subsection{Characterization}

2.3.1. Compressive Strength and Dimensional Stability Tests. $20 \mathrm{~mm} \times 20 \mathrm{~mm} \times 20 \mathrm{~mm}$ and $40 \mathrm{~mm} \times 40 \mathrm{~mm} \times 160 \mathrm{~mm}$ paste samples were prepared according to the mix proportion as shown in Section 2.2. After forming, the samples were cured under standard conditions immediately. The $20 \mathrm{~mm} \times 20 \mathrm{~mm} \times 20 \mathrm{~mm}$ samples were used to measure the compressive strength. After curing for $2 \mathrm{~h}$, the $40 \mathrm{~mm} \times$ $40 \mathrm{~mm} \times 160 \mathrm{~mm}$ samples were removed from the mold, and the initial length was measured and recorded. The expansion ratio was tested by using the method described in literature [23].

2.3.2. Hydration Heat Test. A conduction calorimeter (Thermometric TAM Air) was used to determine the rate of hydration heat liberation during the first $24 \mathrm{~h}$. The specimen was added to a glass container after weighing. Then, the glass container that contained the specimen was placed into the calorimeter. The corresponding amount of water was added when the temperature of specimen was constant at $20^{\circ} \mathrm{C}$. The mixing was done by a small stirrer for $1 \mathrm{~min}$. The total heat of hydration after $24 \mathrm{~h}$ was determined by integration of the heat flow curve.

\subsubsection{X-Ray Diffraction (XRD) and DTA-TG Analysis.} The hydrated specimen was stopped by immersing in alcohol for $24 \mathrm{~h}$. The hydrated specimens were dried by using a vacuum drying box. The temperature and the vacuum degree were $35^{\circ} \mathrm{C}$ and $0.08 \mathrm{MPa}$, respectively. Then, the hydrated specimen was ground by hand below $0.063 \mathrm{~mm}$. An X-ray diffraction analyzer (Smart-Lab, $\mathrm{Cu} \mathrm{k} \alpha$ radiation) was used to determine the mineralogical composition of the hydrated specimen. The test range was $5-80^{\circ}$ at a scanning rate of $10^{\circ} \mathrm{min}$. The DTA-TG curves were tested by using a Hengjiu synchronous thermal instrument with $10^{\circ} \mathrm{C} / \mathrm{min}$ heating rate. The air atmosphere was selected to test the thermal decomposition characteristics of each hydration product, which can guide the thermal stability of grouting materials in practical application environment.

2.3.4. Scanning Electron Microscopy (SEM) Test. Unground specimen was examined by scanning electron microscopy (ZEISS EVO18) using a secondary electron image and energy dispersive X-ray (EDS) analysis. 


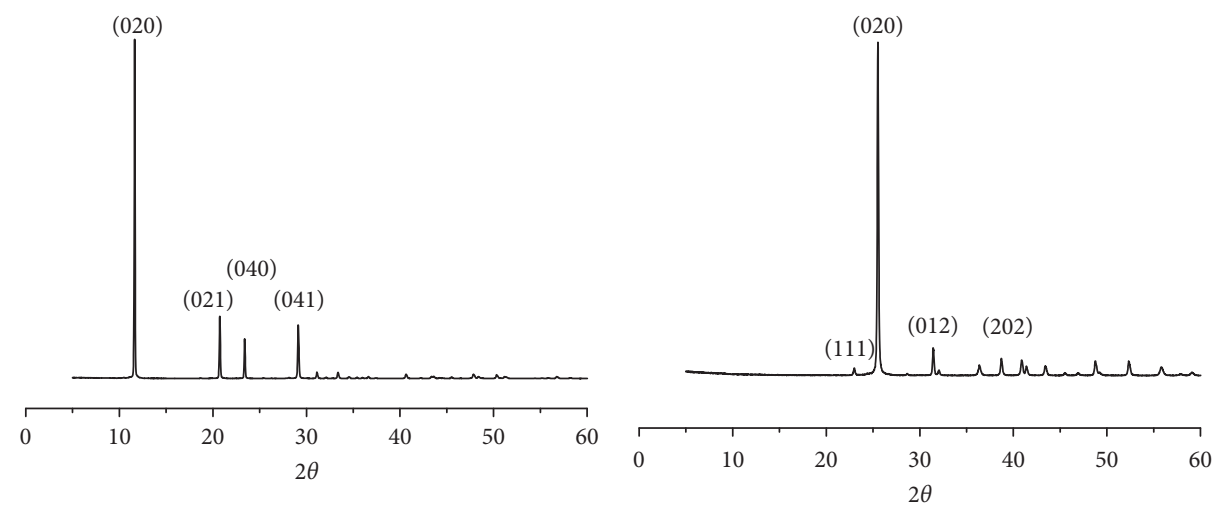

(a)

(b)

FIGURE 1: XRD spectra of two kinds of calcium sulfate resources: (a) gypsum and (b) anhydride.

TABLE 1: Dissolution rate of two kinds of calcium sulfate in saturated lime water.

\begin{tabular}{lccccc}
\hline & $10 \mathrm{~min}$ & $0.5 \mathrm{~h}$ & $4 \mathrm{~h}$ & $8 \mathrm{~h}$ & $1 \mathrm{~d}$ \\
\hline Gypsum $(\mathrm{mmol} / \mathrm{L})$ & 7.4 & 8.2 & 9.1 & 10.9 & 11.5 \\
Anhydrite $(\mathrm{mmol} / \mathrm{L})$ & 3.4 & 4.2 & 5.3 & 6.1 & 7.3 \\
\hline
\end{tabular}

\section{Results and Discussion}

3.1. Isothermal Calorimetry. The hydration exothermic evolution is shown in Figure 2. It can be seen from Figure 2(a) that the hydration exothermic rate can increase rapidly with the increase in hydration time in two specimens and reaching the maximum hydration exothermic rate in a very short time. Subsequently, the hydration exothermic rate decreased rapidly. The maximum exothermic rate of CSA-G is significantly higher than that of CSA-A. The second exothermic peak in CSA-A can be detected after $1.58 \mathrm{~h}$. Figure 2(b) shows the cumulative exothermic curve, and it can be found that the cumulative heat release in the early stage of CSA-G is significantly higher than that in CSA-A. The total heat of hydration is $425.5 \mathrm{~J} / \mathrm{g}$ for CSA-A and $425.1 \mathrm{~J} / \mathrm{g}$ for CSA-G after $24 \mathrm{~h}$, which are very close to each other.

3.2. X-Ray Diffraction Analysis. Figure 3 shows the X-ray diffraction analysis of CSA-G under different hydration ages. It can be seen that strong diffraction peaks of ettringite can be detected only after hydration for $10 \mathrm{~min}$. Thereafter, the diffraction peaks of ettringite gradually increased with the increase in hydration time, but the growth is small. The diffraction peak intensity of ettringite does not increase significantly after $2 \mathrm{~h}$. The diffraction peaks of the gypsum crystal can no longer be detected after $2 \mathrm{~h}$, indicating that it has been depleted. Similarly, the diffraction peak of ye'elimite disappears after $8 \mathrm{~h}$.

Figure 4 shows the X-ray diffraction analysis of CSA-A under different hydration ages. The characteristic peaks of ettringite are obviously weak after $10 \mathrm{~min}$. However, the diffraction peak intensity of ettringite obviously increased with the extension of age. The diffraction peak of ye'elimite gradually weakens with time until it disappeared after 1 day of age. The diffraction peak strength of anhydride also decreases with age, but still can be detected after $28 \mathrm{~d}$. The diffraction peak of gypsum is not detected, indicating that anhydride did not change into gypsum in all ages.

3.3. DTA-TG. The DTA-TG data for CSA-G are shown in Figure 5. The main hydration products are composed of ettringite, monosulfate, and aluminum hydroxide. A strong endothermic peak of ettringite can be detected only at 10 minutes of hydration. The endothermic peak of ettringite does not change significantly after $2 \mathrm{~h}$. The endothermic peak of gypsum is near $150^{\circ} \mathrm{C}$, which cannot be detected after $2 \mathrm{~h}$. Besides, a small amount of monosulfate was detected at all ages. On the whole, the results of thermal analysis and XRD show the same rule.

Figure 6 shows the DTA-TG curves for CSA-G at different ages. It can be seen that the main hydration products of CSA-A also included ettringite, monosulfate, and aluminum hydroxide. Unlike CSA-G, only little ettringite is detected after $10 \mathrm{~min}$ in CSA-A. However, the amount of ettringite can increase rapidly with the prolongation of age. The gypsum cannot be detected throughout the age period. These thermal analysis results of CSA-A are also consistent with the XRD results. Besides, the monosulfate disappears after $7 \mathrm{~d}$, possibly all of them converted into ettringite.

According to the method described in literature [26], the content of ettringite in two groups of specimen is calculated, which is shown in Figure 7. For CSA-G, the production of ettringite is as high as $67 \mathrm{wt}$. \% after 10 minutes of hydration. The production of ettringite is the largest $2 \mathrm{~h}$ later, which is about 80.7 wt. \%. Thereafter, the amount of ettringite hardly changed with age. For CSA-A, the amount of ettringite is only $11.4 \mathrm{wt}$. \% after $10 \mathrm{~min}$ of hydration, which is significantly lower than CSA-G. However, the production of ettringite in CSA-A can increase by a large margin. The amount of ettringite in CSA-A reaches the maximum until $7 \mathrm{~d}$. The great difference in the formation law of ettringite in two groups may be related to the dissolution rate of gypsum and anhydride. The dissolution rate of gypsum is faster than that of anhydride, which may be the reason for the formation of more ettringite in CSA-G in the early age. 


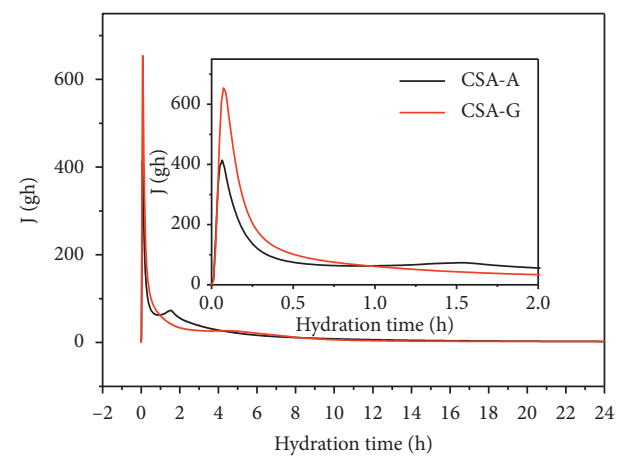

(a)

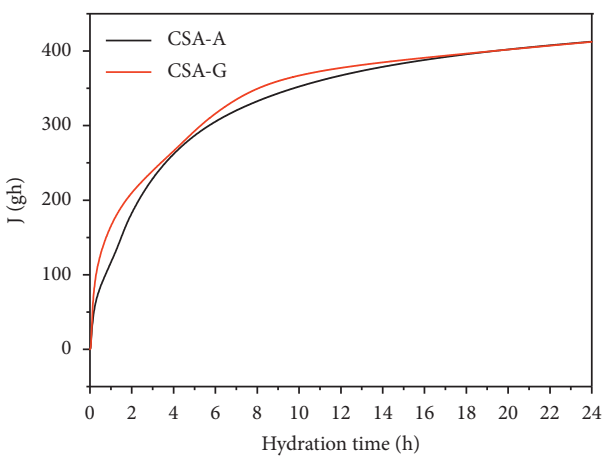

(b)

Figure 2: Hydration exothermic curve: (a) exothermic rate curve; (b) cumulative exothermic curve.

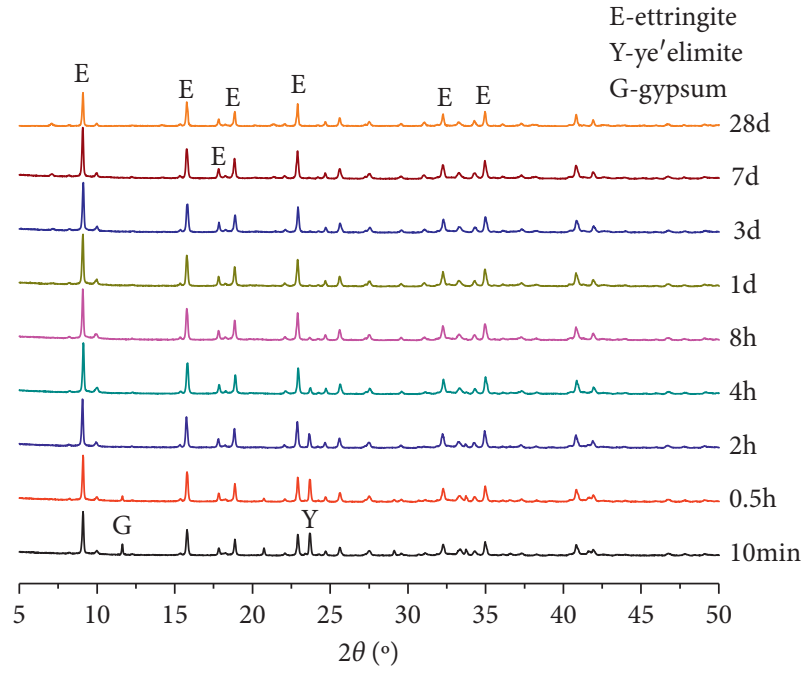

Figure 3: X-ray diffraction analysis of CSA-G under different hydration ages.

3.4. SEM-EDS Analysis. In Figure 8, SEM images and EDS analysis for hydrated CSA-G and CSA-A are reported, respectively, at $10 \mathrm{~min}$ and $28 \mathrm{~d}$ of curing time. From Figures 8(a) and 8(b), a large number of acicular ettringite $(0.5 \mu \mathrm{m}$ wide, generally $2 \mu \mathrm{m}$ length) can be observed in CSA-G after 10 min of hydration. The majority of acicular ettringite tended to be precipitated around the clinker grain, which can effectively reduce the bridging effect of ettringite. Even, partial ettringite is formed in the shape of a stellate cluster. From Figures 8(c) and 8(d), the acicular ettringite (0.5 $\mu \mathrm{m}$ wide, $2-3 \mu \mathrm{m}$ length) also can be precipitated in CSA-A after $10 \mathrm{~min}$ of hydration. However, the concentration of ettringite in CSA-A is obviously less than that of the CSA-G specimen. Besides, ettringite is distributed uniformly in the CSA-A matrix, showing complex overlapping between each other. As can be seen from Figures 8(e) and $8(\mathrm{f})$, a large number of amorphous hydration products are observed in CSA-G and CSA-A after $28 \mathrm{~d}$ of hydration,

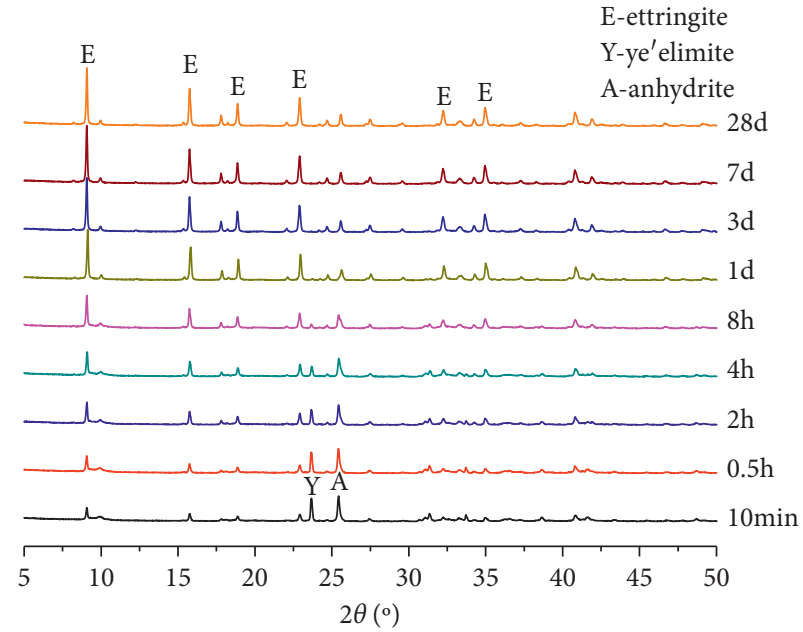

FIgure 4: X-ray diffraction analysis of CSA-A under different hydration ages.

which is determined as $\mathrm{AH}_{3}$ gel and C-S-H gel by EDS analysis, as shown in Figures $8(\mathrm{~g})$ and $8(\mathrm{~h})$. The density of the matrix of two specimens increase significantly compared with the early stage.

3.5. Compressive Strength. Figure 9 gives the compressive strength results. For the CSA-G specimen, the compressive strength gradually increases with the extension of the hydration age. However, the compressive strength of CSA-G is no longer significantly enhanced after $3 \mathrm{~d}$. The maximum compressive strength is $8.3 \mathrm{MPa}$ ultimately. For CSA-A, the compressive strength gradually increases in the hydration stage of $4 \mathrm{~h}$ to $3 \mathrm{~d}$. After $3 \mathrm{~d}$, the compressive strength of CSA-A keeps constant until $28 \mathrm{~d}$ and continued to increase, which is $17.4 \mathrm{MPa}$. Obviously, the ultrafine sulfoaluminate cement-based grouting materials have significantly higher mechanical properties when anhydride is selected. 


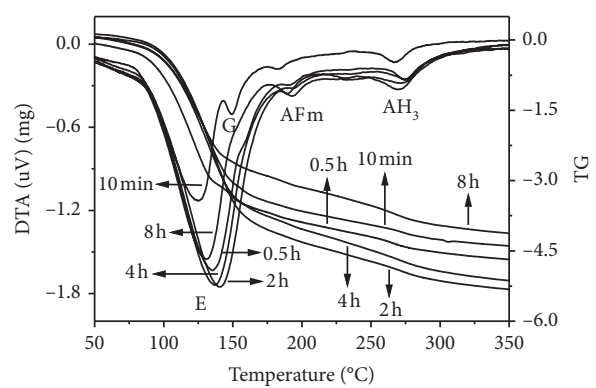

(a)

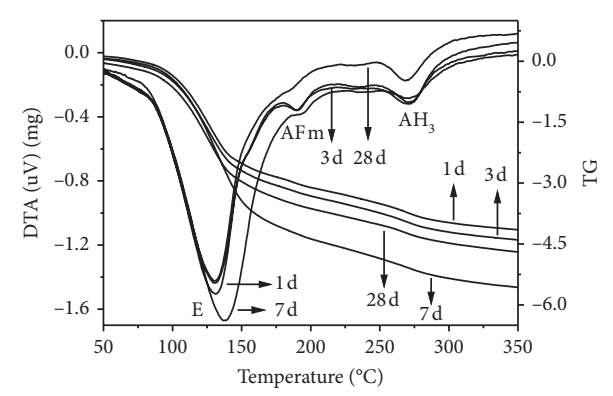

(b)

FIgURE 5: Synchronous thermal analysis of CSA-G under different hydration ages.

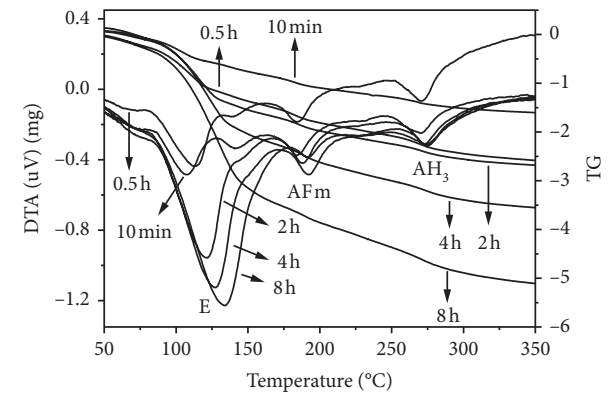

(a)

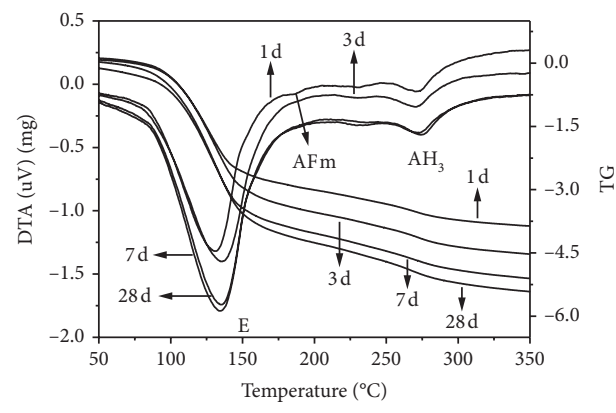

(b)

FIgURE 6: Synchronous thermal analysis of CSA-A under different hydration ages.

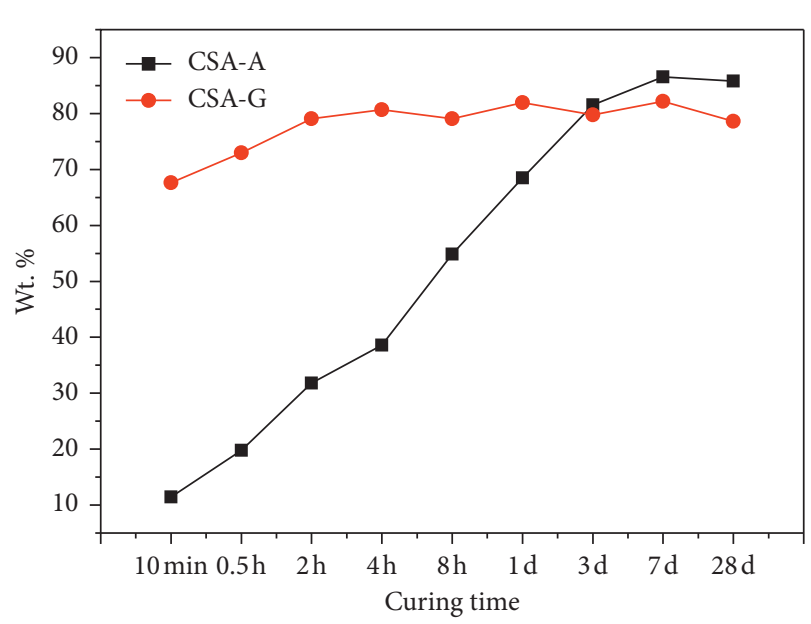

FIGURE 7: Change regulation of ettringite quantity with curing age.

The strength of sulfoaluminate cement mainly comes from the formation of ettringite. In general, the more the amount of ettringite, the higher the mechanical strength in the sulfoaluminate cement system. However, it can be found that the evolution of compressive strength values of CSA-G and CSA-A is never in complete agreement with the ettringite formation in the early hydration stage, as shown in Figures 7 and 9. Although a large amount of ettringite formation occurs in CSA-G at early hydration process, the early strength values of CSA-G are obviously lower than that of CSA-A. In fact, the distribution of ettringite also affects the strength of the hardened body. For CSA-G, despite a large number of ettringite precipitated in the early age, the fine acicular ettringite tends to be congregated around the clinker grain, which may effectively reduce the bridging effect between ettringite crystals, producing a negative effect on the compressive strength of the hardened body. For CSA-A, although only a small amount of ettringite is formed at the early hydration process, the precipitated ettringite can be uniformly distributed in CSAA, showing complex overlapping between each other and ensuring good "skeleton effect" of ettringite, which may have a positive effect on the compressive strength of the hardened body.

3.6. Expansion Test. The expansion ratio results are shown in Figure 10. For CSA-A, the hardened body shows significant expansion characteristic, and the expansion ratio is gradually increased with the extension of the hydration age. However, it is $1 \mathrm{~d}$ or so later that the expansion ratio of CSA$\mathrm{A}$ is no longer significantly changed. The hardened body for the CSA-G specimen only shows very slight shrinkage characteristics during the early hydration stage. Then, the shrinkage ratio decreases in the later hydration stage. The hardened body had nearly the same volume as in initial time after $28 \mathrm{~d}$ of hydration.

The expansion ratio depends on the amount of ettringite. In the CSA-A specimen, the ettringite crystal always can be 


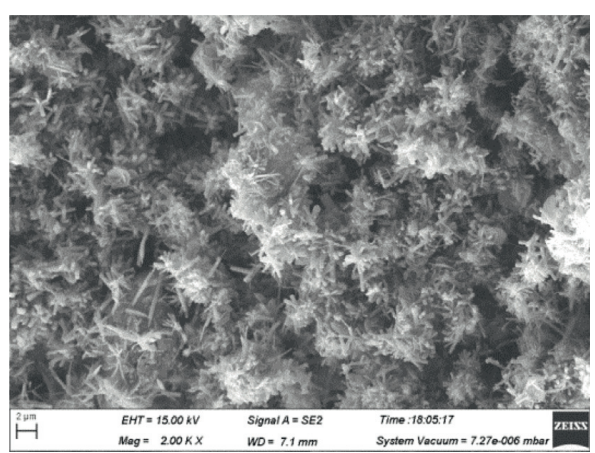

(a)

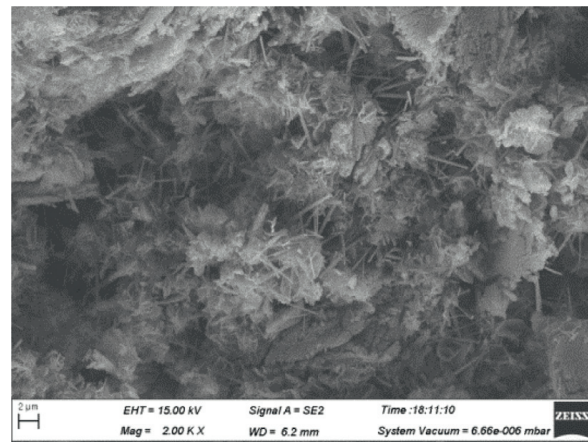

(c)

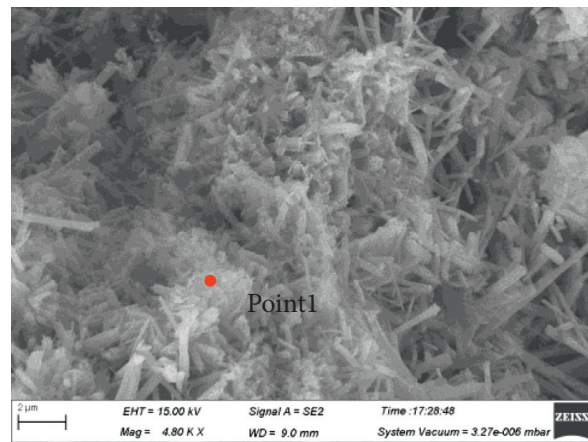

(e)

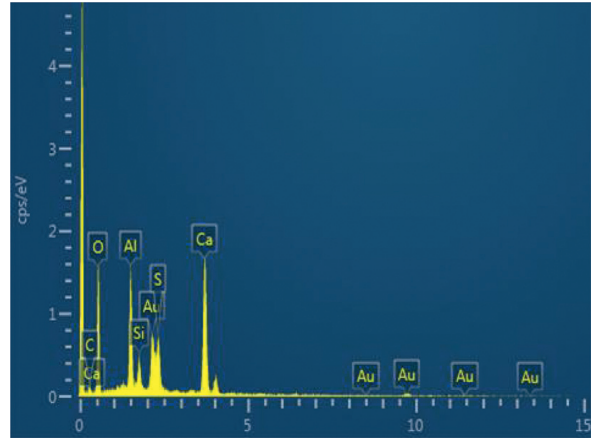

(g)

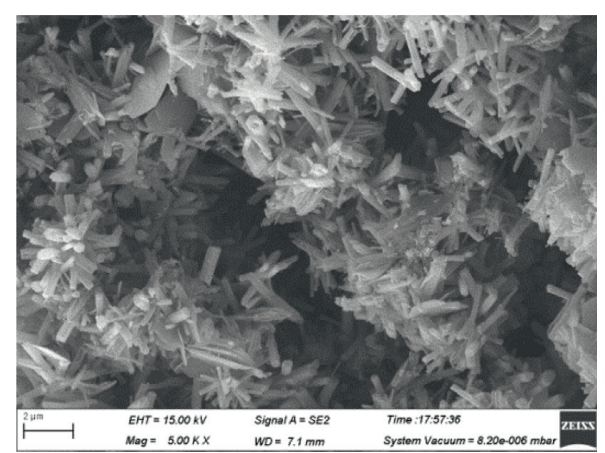

(b)

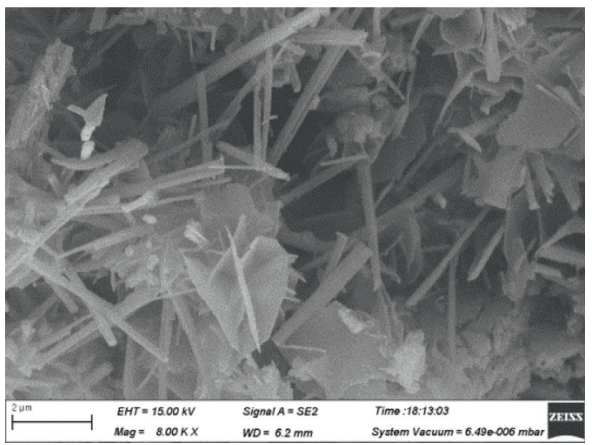

(d)

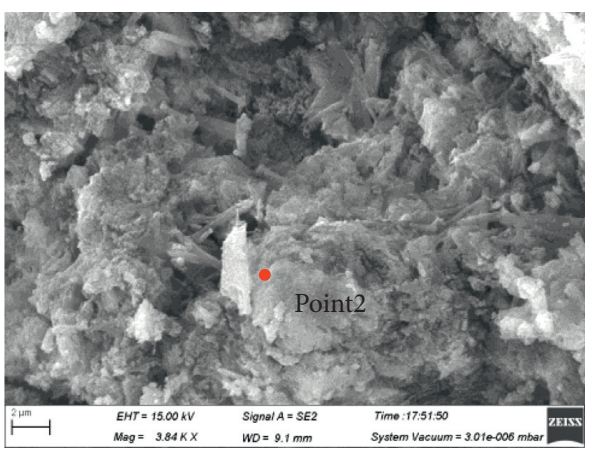

(f)

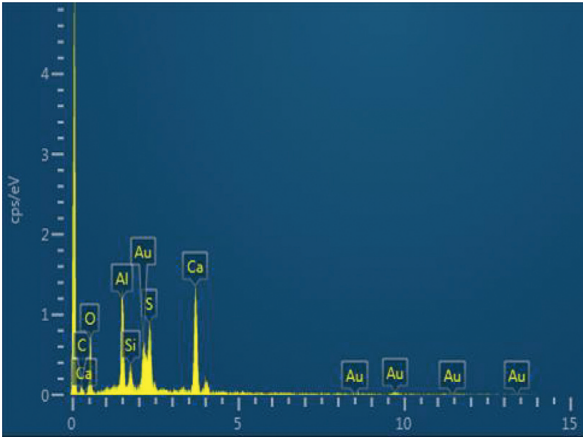

(h)

FIgURE 8: Effect of calcium sulfate variety on the morphology of ettringite: (a) CSA-G for $10 \mathrm{~min}$; (b) CSA-G for $10 \mathrm{~min}$; (c) CSA-A for $10 \mathrm{~min}$; (d) CSA-A for $10 \mathrm{~min}$; (e) CSA-G for $28 \mathrm{~d}$; (f) CSA-A for $28 \mathrm{~d}$; (g) Point 1 EDS; (h) Point 2 EDS.

formed at a very higher rate in the $2 \mathrm{~h}-1 \mathrm{~d}$ hydration age period, causing a significant increase in the expansion ratio. For the CSA-G specimen, most hydration reactions related to ettringite were completed in a very short time, which caused only little ettringite to be formed after $2 \mathrm{~h}$ of hydration, effectively leading to nonexpansion characteristics. 


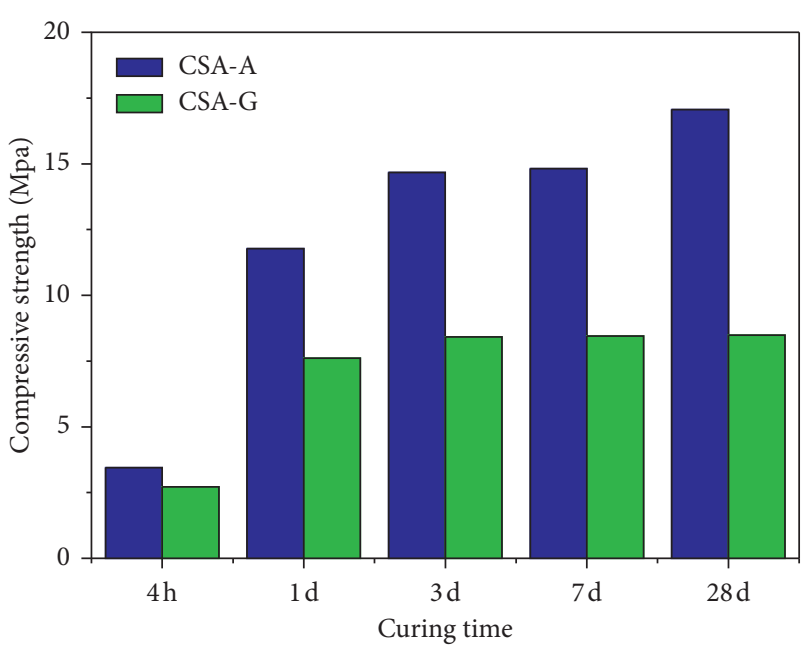

Figure 9: Compressive strength test results.

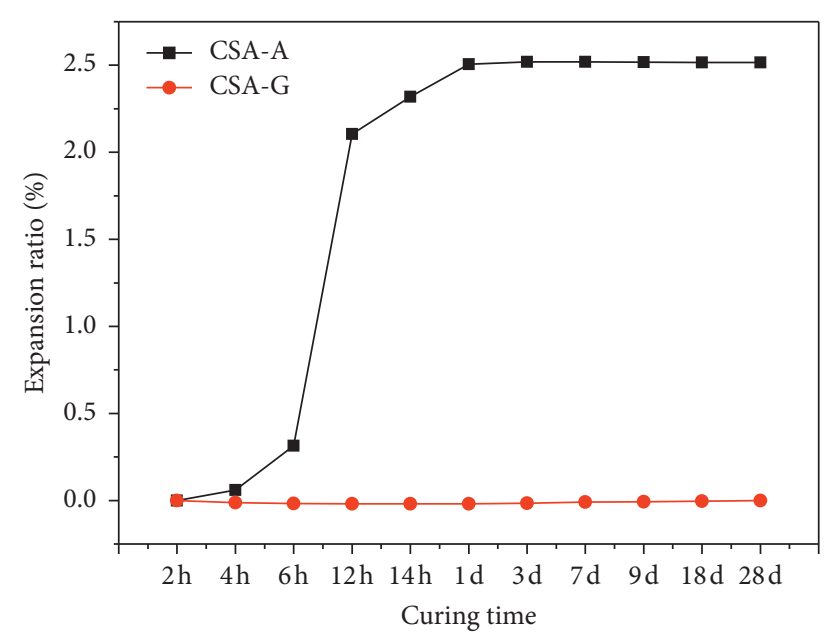

Figure 10: Expansion ratio test results.

\section{Conclusions}

In this study, the effect of calcium sulfate variety on the microstructure and properties of sulfoaluminate cementbased grouting material was investigated. The chief conclusions to be drawn from the present study are as follows.

Due to the relatively faster dissolution rate of gypsum, the formation process of ettringite can be completed during the first $2 \mathrm{~h}$ of hydration when gypsum is selected as the calcium sulfate source, causing nonexpansion characteristic of the hardened body in the later stage of hydration. In addition, ettringite tends to be precipitated near the clinker grain, which may have a negative influence on the "skeleton effect" of ettringite, bringing about adverse effects on the mechanical property of the hardened body.
Anhydrite has a relatively slower dissolution rate; thus, ettringite can be continually precipitated with the extension of the hydration age when anhydride is chosen, effectively resulting in a significant expansion. Besides, the precipitated ettringite can be uniformly distributed, showing complex interleaving, which can guarantee good "skeleton bridging effect" of ettringite and has a positive influence on the mechanical property.

\section{Data Availability}

The data used to support the findings of this study are available from the corresponding author upon request.

\section{Conflicts of Interest}

The authors declare that they have no conflicts of interest.

\section{Acknowledgments}

This work was vigorously supported by the National Key R\&D Program of China (Grant no. 2017YFC0603004) and Henan Provincial Solid Waste Comprehensive Disposal and Ecological Utilization Collaborative Innovation Center Open Project Funded Project (Grant no. XT201904).

\section{References}

[1] F. P. Glasser and L. Zhang, "High-performance cement matrices based on calcium sulfoaluminate-belite compositions," Cement and Concrete Research, vol. 31, no. 12, pp. 1881-1886, 2001.

[2] M. C. G. Juenger, F. Winnefeld, J. L. Provis, and J. H. Ideker, "Advances in alternative cementitious binders," Cement and Concrete Research, vol. 41, no. 12, pp. 1232-1243, 2011.

[3] Y. J. Liu, Y. M. Xu, and C. L. Geng, "Sulfoaluminate cement: an alternative to Portland cement," Advanced Materials Research, vol. 368-373, pp. 478-484, 2011.

[4] P. Arjunan, M. Silsbee, and D. M. Roy, "Sulfoaluminate-belite cement from low-calcium fly ash and sulfur-rich and other industrialby-products," Cement and Concrete Research, vol. 29, pp. 1305-1311, 1999.

[5] E. Gartner, "Industrially interesting approaches to "low-CO2" cements," Cement and Concrete Research, vol. 34, no. 9, pp. 1489-1498, 2004.

[6] H. Ludwig and W. Zhang, "Research review of cement clinker chemistry," Cement and Concrete Research, vol. 78, pp. 24-37, 2015.

[7] O. Andac and F. P. Glasser, "Microstructure and microchemistry of calcium sulfoaluminate cement," MRS Proceedings, vol. 370, pp. 135-142, 1994.

[8] I. Janotka, L. Krajci, and S. C. Mojumdar, "Performance of sulphoaluminate-belite cement with high $\mathrm{C}_{4} \mathrm{~A}_{3} \overline{\mathrm{S}}$ contents," Ceramics Silikaty, vol. 51, no. 2, p. 74, 2007.

[9] D. Adolfsson, N. Menad, E. Viggh, and B. Björkman, "Hydraulic properties of sulphoaluminate belite cement based on steelmaking slags," Advances in Cement Research, vol. 19, no. 4, pp. 133-138, 2007.

[10] W. Lan and F. P. Glasser, "Hydration of calcium sulphoaluminate cements," Advances in Cement Research, vol. 8, no. 31, pp. 127-134, 1996. 
[11] L. Zhang and F. P. Glasser, "Hydration of calcium sulfoaluminate cement at less than $24 \mathrm{~h}$," Advances in Cement Research, vol. 14, no. 4, pp. 141-155, 2002.

[12] G. Bernardo, A. Telesca, and G. L. Valenti, “A porosimetric study of calcium sulfoaluminate cement pastes cured at early ages," Cement and Concrete Research, vol. 36, no. 6, pp. 1042-1047, 2006.

[13] Y. Liao, X. Wei, and G. Li, "Early hydration of calcium sulfoaluminate cement through electrical resistivity measurement and microstructure investigations," Construction and Building Materials, vol. 25, no. 4, pp. 1572-1579, 2011.

[14] K. Quillin, "Performance of belite-sulfoaluminate cements," Cement and Concrete Research, vol. 31, no. 9, pp. 1341-1349, 2001.

[15] S. W. Tang, H. G. Zhu, Z. J. Li, E. Chen, and H. Y. Shao, "Hydration stage identification and phase transformation of calcium sulfoaluminate cement at early age," Construction and Building Materials, vol. 75, pp. 11-18, 2015.

[16] D. Min and T. Mingshu, "Formation and expansion of ettringite crystals," Cement and Concrete Research, vol. 24, no. 1, pp. 119-126, 1994.

[17] I. A. Chen, C. W. Hargis, and M. C. G. Juenger, "Understanding expansion in calcium sulfoaluminate-belite cements," Cement and Concrete Research, vol. 42, no. 1, pp. 51-60, 2012.

[18] M. C. G. Juenger, F. Winnefeld, J. L. Provis, and J. H. Ideker, "Advances in alternative cementitious binders," Cement and Concrete Research, vol. 41, no. 12, pp. 1232-1243, 2011.

[19] H. Ludwig and W. Zhang, "Research review of cement clinker chemistry," Cement and Concrete Research, vol. 78, pp. 24-37, 2015.

[20] A. Telesca, "A hydration study of various calcium sulfoaluminate cements," Cement and Concrete Composites, vol. 53, pp. 224-232, 2014.

[21] O. Martín-Sede, "Aluminum-rich belite sulfoaluminate cements: clinkering and early age hydration," Cement and Concrete Research, vol. 40, no. 3, pp. 359-369, 2010.

[22] F. Winnefeld and B. Lothenbach, "Hydration of calcium sulfoaluminate cements - Experimental findings and thermodynamic modelling," Cement and Concrete Research, vol. 40, no. 8, pp. 1239-1247, 2010.

[23] J. Zhang, X. Guan, H. Li, and X. Liu, "Performance and hydration study of ultra-fine sulfoaluminate cement-based double liquid grouting material," Construction and Building Materials, vol. 132, pp. 262-270, 2017.

[24] M. García-Maté, A. G. De la Torre, L. León-Reina, E. R. Losilla, M. A. G. Aranda, and I. Santacruz, "Effect of calcium sulfate source on the hydration of calcium sulfoaluminate eco-cement," Cement and Concrete Composites, vol. 55, pp. 53-61, 2015.

[25] F. Winnefeld and S. Barlag, "Influence of calcium sulfate and calcium hydroxide on the hydration of calcium sulfoaluminate clinker," ZKG International, vol. 12, pp. 42-53, 2009.

[26] B. Lothenbach and E. Wieland, "A thermodynamic approach to the hydration of sulphate-resisting Portland cement," Waste Management, vol. 26, no. 7, pp. 706-719, 2006. 